\title{
Hubungan Tingkat Pengetahuan dan Perilaku Penggunaan Sampo Terhadap Kejadian Pedikulosis Kapitis di Panti Asuhan X Palangka Raya
}

\author{
Reza Kurnia Rahmawati ${ }^{1}$, Astrid Teresa ${ }^{2}$, Dian Mutiasari ${ }^{3}$, Helena Jelita ${ }^{4}$, Indria Augustina ${ }^{5}$ \\ 1 Mahasiswa Fakultas Kedokteran Universitas Palangka Raya, Palangka Raya, Indonesia \\ 2,3,4,5 Dosen Fakultas Kedokteran Universitas Palangka Raya, Palangka Raya, Indonesia \\ *Corresponding author: reza1820kurnia@gmail.com
}

\begin{abstract}
Background: Pediculosis capitis is a scalp or hair infection in humans caused by Pediculus humanus capitis. The disease primarily affects childern and rapidly expanding in dense living environments, such as dormitories and orphanages. The purpose of this research is to know the relationship between level of knowledge and shampoo usage behavior on the incidence of pediculosis capitis in X Palangka Raya Orphanage. Method: This research was used a cross sectional approach, conducted in September 2019. Sampling techniques are performed with purposive sampling techniques. The variables studied are the level of knowledge and shampoo usage behavior. Relationship of each variable to the incidence of pediculosis capitis is measured using bivariate analysis. Research results: Based on the results of physical examination and microscopic examination was found 31 respondents (88.6\%) positive of pediculosis capitis, which is based on the Chi-square test, the level of knowledge with the incidence of pediculosis capitis has $p$ value= 0.285 , and shampoo usage behavior with the incidence of pediculosis capitis has p value $=0.274$. Conclusion: There is no correlation between level of knowledge and shampoo usage behavior with the incidence of pediculosis capitis in $X$ Palangka Raya Orphanage
\end{abstract}

Keyword: Pediculosis capitis, level of knowledge, shampoo usage behavior, X Palangka Raya Orphanage

\section{PENDAHULUAN}

Pedikulosis kapitis adalah infeksi kulit kepala atau rambut pada manusia yang disebabkan oleh Pediculus humanus capitis, sering disebut juga sebagai penyakit kutu kepala. Penyakit ini terutama menyerang anak-anak usia muda dan cepat meluas dalam lingkungan hidup yang padat, misalnya asrama dan panti asuhan. ${ }^{1}$ Pedikulosis kapitis biasanya menyerang populasi anak dengan kelompok usia 6-12 tahun. Perempuan memiliki risiko terinfeksi 2-4 kali lebih besar dibandingkan laki-laki, terutama pada orang yang memiliki rambut panjang yang tinggal di daerah pedesaan. ${ }^{2}$ Infestasi kutu dapat menyebabkan dampak berupa iritasi pada kulit kepala dan gangguan seperti berkurangnya konsentrasi belajar, berkurangnya kualitas tidur di malam hari akibat rasa gatal dan gangguan sosial seperti rasa rendah diri dan malu. ${ }^{3}$

Prevalensi dan insidensi pedikulosis kapitis di seluruh dunia cukup tinggi, baik di negara berkembang maupun negara maju. Diperkirakan ada ratusan juta orang yang terinfeksi pedikulosis kapitis setiap tahunnya.
Pada tahun 2008 di negara Turki prevalensinya berkisar $0,7-59 \%$, di Eropa 0,48\%-22,4\%, di Australia 13\%, di Afrika $58,9 \%$, dan di Amerika 3,6-61,4\%. ${ }^{4}$ Penelitian di Asia Tenggara yaitu negara Thailand pada tahun 2012 menunjukkan prevalensi sebesar $23,32 \%$, dengan prevalensi tertinggi pada perempuan. ${ }^{5}$ Penelitian di negara asia tenggara yang lain yaitu negara Malaysia pada tahun 2006 didapatkan prevalensi pedikulosis kapitis mencapai $35 \%$. $^{6}$ Persentase penderita pedikulosis di Indonesia belum diketahui secara pasti. Penelitian yang pernah dilakukan di Indonesia pada tahun 2010 menunjukkan $71,3 \%$ putri yang tinggal di asrama di Yogyakarta terinfeksi pedikulosis kapitis. ${ }^{7}$

Faktor-faktor yang meningkatkan resiko terjadinya pedikulosis kapitis antara lain yaitu jenis kelamin, frekuensi cuci rambut, penggunaan sisir atau aksesoris rambut bersama, penggunaan alas atau tempat tidur bersama, panjang rambut, dan jenis rambut. ${ }^{9}$ Penelitian yang dilakukan oleh Ansyah di Pondok Pesantren Modern Islam Assalam 
menunjukkan terdapat hubungan antara kebersihan diri dengan kejadian pedikulosis kapitis, dengan angka kejadian pedikulosis kapitis sebesar $72,1 \% .^{10}$

Pediculus humanus capitis menyukai kulit kepala dan rambut yang lembab. Pada anak terjadi peningkatan hormon dehidroepiandrosteron pada awal sebelum pubertas yaitu sekitar usia 8 tahun dan meningkat 10 kali lipat diusia 10 tahun. ${ }^{11}$ Peningkatan hormon ini memicu peningkatan sekresi sebum oleh glandula sebasea yang akan mengakibatkan kulit kepala dan rambut menjadi lebih lembab. Untuk mengatasi kelembaban yang berlebih maka diperlukan cara penggunaan sampo yang tepat. Pedikulosis kapitis mudah menyerang anakanak, hal ini karena anak-anak tidak terlalu serius memperhatikan kebersihan tubuhnya. Penelitian yang dilakukan oleh Lesshaft menunjukkan hasil bahwa anak dengan usia $\leq 15$ tahun memiliki risiko lebih tinggi untuk terkena pedikulosis kapitis dibanding usia lebih dari 15 tahun. $^{12}$

Berdasarkan data dari Dinas Sosial Kota Palangka Raya tahun 2019 diketahui bahwa terdapat 28 lembaga kesejahteraan sosial yang terdiri dari 19 panti asuhan di Kota Palangka Raya, salah satunya adalah Panti Asuhan $\mathrm{X}$ yang memiliki anak asuh terbanyak yaitu 111 anak asuh. Penelitian dilakukan di panti asuhan, karena berdasarkan survei lapangan diketahui bahwa aktivitas sehari-hari anak asuh banyak dilakukan bersama dan ruangan tempat tidur dihuni oleh beberapa orang dalam satu ruangan. Penelitian dilakukan di Panti Asuhan X karena panti asuhan ini memiliki jumlah anak asuh yang paling banyak dan memiliki jumlah anak asuh sesuai dengan kriteria yang ingin diteliti. Menurut informasi dari pengurus Panti Asuhan X, kutu kepala seringkali ditemukan pada anak-anak asuh terutama perempuan, hal ini dapat muncul kapan saja dan sebelumnya belum pernah mendapatkan penyuluhan mengenai kutu kepala di Panti Asuhan ini.

Berdasarkan hal-hal tersebut, maka penulis mengusulkan penelitian yang berjudul hubungan tingkat pengetahuan dan perilaku penggunaan sampo terhadap kejadian pedikulosis kapitis di Panti Asuhan X Palangka Raya.

\section{METODE PENELITIAN}

Rancangan penelitian yang digunakan dengan pendekatan cross sectional yang dilakukan pada bulan September 2019. Teknik pengambilan sampel dilakukan dengan teknik purposive sampling dengan jumlah responden sebanyak 35 anak perempuan. Instrumen pengambilan data menggunakan kuesioner dan pemeriksaan fisik serta pemeriksaan mikroskopik. Variabel yang diteliti adalah tingkat pengetahuan dan perilaku penggunaan sampo. Hubungan dari tiap variabel terhadap kejadian pedikulosis kapitis diukur menggunakan analisis bivariat dengan menggunakan uji Chi-square.

\section{HASIL DAN PEMBAHASAN}

Usia.

Pada gambar 1. menunjukkan bahwa persentasi terbanyak responden menurut usia terdapat pada usia 14 tahun yaitu sebanyak 14 orang $(40 \%)$ dari 35 responden, dan paling sedikit yaitu anak usia 11 tahun sebanyak 1 orang $(2,9 \%)$.

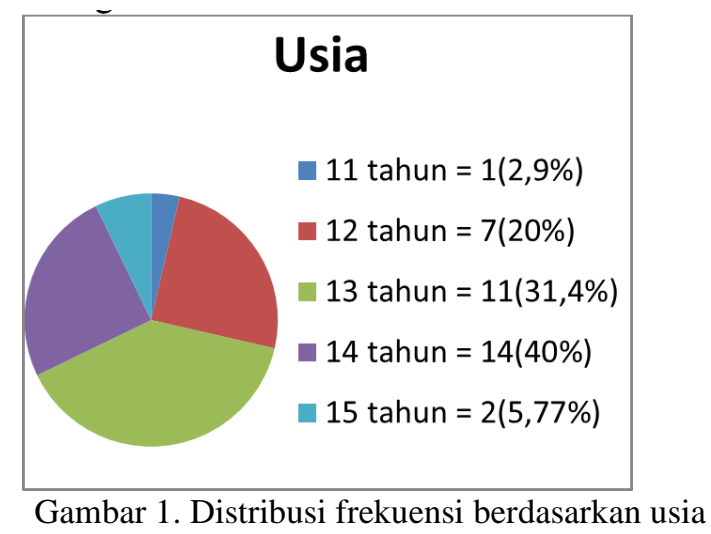

Usia responden terbanyak adalah usia 14 tahun sebanyak $14(40 \%)$ responden. Usia tersebut tergolong kedalam usia remaja awal yang merupakan awal dari perkembangan menjadi dewasa sehingga berkembang pula kognitifnya yang mempengaruhi cara berperilaku dan bersikap. Pada tahap remaja awal maka telah terjadi suatu peningkatan 
berupa perubahan cara bersikap salah satunya adalah kemandirian. Hasil frekuensi distribusi responden dalam penelitian ini sesuai dengan penelitian Lukman dkk, di Pondok Pesantren Miftahul Ulum Kabupaten Jember yang menyatakan bahwa responden terbanyak adalah usia 14-16 tahun sebanyak 144 (50,2\%) responden. ${ }^{9}$

\section{Tingkat Pengetahuan}

Pada gambar 2. menunjukkan nilai pengetahuan baik sebanyak 24 responden $(68,6 \%)$ dan pengetahuan kurang sebanyak 11 responden $(31,4 \%)$. Berdasarkan hasil tersebut maka dapat dikatakan bahwa pengetahuan responden mengenai pedikulosis kapitis paling banyak adalah baik.

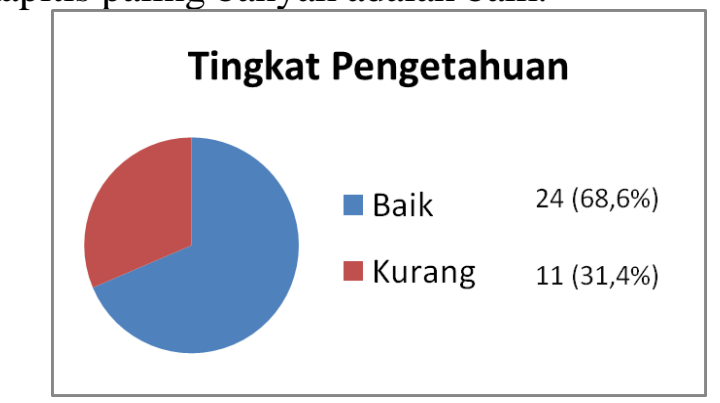

Gambar 2. Distribusi Responden Berdasarkan Tingkat Pengetahuan

Pengetahuan responden dalam penelitian ini paling banyak adalah baik sebanyak $24(68,6 \%)$ responden. Pengetahuan yang tinggi dipengaruhi pula oleh usia, dimana responden terbanyak adalah usia 14 tahun yang tergolong remaja awal. Remaja merupakan masa transisi atau peralihan dari masa anak menuju masa dewasa yang disertai pula dengan perubahan kognitif, dimana remaja mulai mampu berfikir abstrak seperti orang dewasa. Sehingga anak usia tersebut lebih banyak menangkap informasi yang didapat baik dari sekolah maupun pengalaman dirinya maupun orang disekitarnya dan semakin bertambah usia semakin bertambah pula pengetahuannya. Hasil distribusi tingkat pengetahuan dalam penelitian ini sesuai dengan penelitian Anggraini dkk, di Panti Asuhan Liga Dakwah Sumatera Barat dengan persentase tingkat pengetahuan tinggi terbanyak yaitu sebanyak $61(88,4 \%)$ responden. ${ }^{59}$

\section{Perilaku Penggunaan Sampo.}

Pada gambar 3. Menunjukkan adanya perilaku baik sebanyak 22 responden $(62,9 \%)$ dan perilaku kurang sebanyak 13 responden $(37,1 \%)$. Berdasarkan hasil tersebut maka dapat dikatakan bahwa perilaku penggunaan sampo responden paling banyak adalah baik.

\section{Perilaku Penggunaan Sampo}

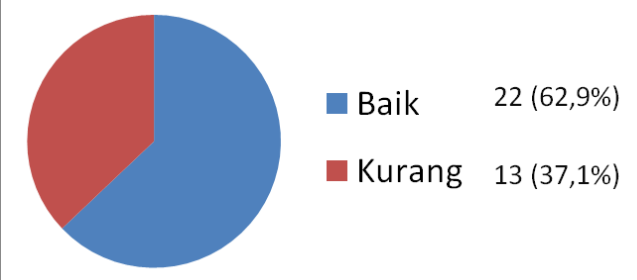

Gambar 3. Distribusi Berdasarkan Tingkat Pengetahuan

Perilaku penggunaan sampo terbanyak adalah baik sebanyak 22 (62,9\%), responden hal ini karena perilaku dipengaruhi oleh beberapa faktor diantaranya faktor predisposisi seperti pengetahuan, keyakinan dan kepercayaan, faktor pemungkin seperti ekonomi serta sarana dan prasarana, dan faktor penguat seperti tokoh masyarakat atau seseorang yang membuatnya menirukan apa yang mereka lakukan. Dengan tingkat pengetahuan yang tinggi maka hal ini pula mempengaruhi perilaku responden. Sehingga dengan pengetahuan yang mereka miliki mereka dapat mengaplikasikannya menjadi sebuah perilaku. Menurut Notoatmodjo jika seseorang dapat mengaplikasikan apa yang telah ia ketahui maka hal tersebut digolongkan sebagai pengetahuan pada tingkatan ketiga yaitu aplikasi. ${ }^{63}$

Hasil distribusi perilaku penggunaan sampo dalam penelitian ini sesuai dengan penelitian Dita, di Pondok Pesantren Aulia Cendekia Talang Jambe Sukarami Palembang dengan persentase higiene cuci rambut baik terbanyak yaitu sebesar $96 \quad(84,2 \%)$ responden. ${ }^{61}$

\section{Kejadian Pedikulosis Kapitis.}

Pada gambar 4. berdasarkan hasil pemeriksaan fisik dan pemeriksaan mikroskopis didapatkan hasil yaitu ditemukan 31 responden $(88,6 \%)$ positif, dan 4 responden $(11,4 \%)$ negatif. 


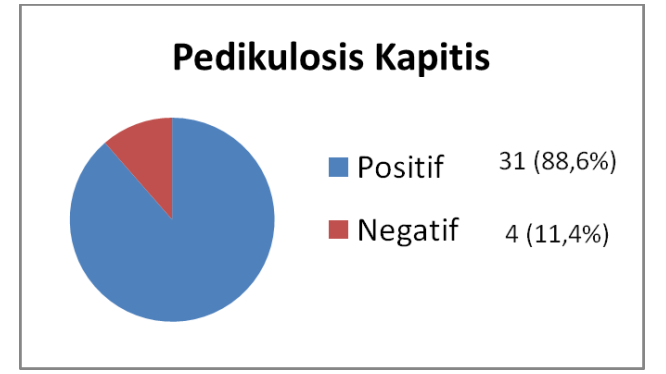

Gambar 4. Distribusi Kejadian Pedikulosis Kapitis

Hasil penelitian ini sesuai dengan penelitian Aisy, di Pondok Pesantren X Yogyakarta didapatkan angka kejadian pedikulosis kapitis sebanyak 73 (59,8\%) responden, terhadap responden usia 13-17 tahun. ${ }^{66}$

\section{Hubungan Tingkat Pengetahuan dengan Kejadian Pedikulosis Kapitis}

Pada Tabel 1. Berdasarkan uji Fisher's Exact Test antara tingkat pengetahuan dengan kejadian pedikulosis kapitis didapatkan nilai $\mathrm{p}=0,285$ atau $\mathrm{p}>0,05$ sehingga $\mathrm{H}_{0}$ diterima yang menandakan bahwa tidak terdapat hubungan antara tingkat pengetahuan dengan kejadian pedikulosis kapitis.

Tabel 1. Hubungan Tingkat Pengetahuan Dengan

Kejadian Pedikulosis Kapitis

\begin{tabular}{ccccccc}
\hline & Tingkat & \multicolumn{4}{c}{ Kejadian Pedikulosis Kapitis } & \\
\cline { 3 - 6 } No. Nilai p \\
\cline { 3 - 6 } & Pengetahuan & Positif & $\%$ & Negatif & $\%$ & \\
\hline 1 & Baik & 20 & 83,3 & 4 & 16,7 & \\
2 & Kurang & 11 & 100 & 0 & 0 & \\
\hline
\end{tabular}

Sumber : Data Primer, 2019

Pengetahuan pula tidak mencerminkan secara keseluruhan mengenai perilaku seseorang. Pendidikan dan pengetahuan yang tinggi tidak menjamin perilaku seseorang karena tingkat pengetahuan seseorang dibagi menjadi 6 yaitu tahu, memahami, mengaplikasikan, menganalisa, mensintesis, dan mengevaluasi terhadap materi yang berkaitan dengan suatu kejadian. Jika pengetahuan seseorang hanya sampai tingkat tahu maka pengetahuan yang ia dapatkan tersebut belum tentu dipahami maupun diaplikasikan. Hal ini tergambar dalam kuesioner dimana pada tabel 5.3 disebutkan bahwa terdapat 20 orang $(83,3 \%)$ positif pedikulosis kapitis yang memiliki pengetahuan baik. Namun terdapat 20 orang $(57,1 \%)$ dari seluruh responden yang masih menggunakan sisir bergantian dengan orang lain, 18 orang $(51,4 \%)$ dari seluruh responden yang masih menggunakan jilbab bergantian dengan orang lain, 18 orang $(51,4 \%)$ dari seluruh responden yang tidur satu kasur dengan orang lain, dan 18 orang $(51,4 \%)$ dari seluruh responden saling meminjam perlatan tidur orang lain. Hal inilah yang menyebabkan responden dengan pengetahuan baik tetap terkena pedikulosis kapitis, karena perilaku menggunakan barang pribadi bergantian dengan orang lain adalah faktor resiko untuk terjadi pedikulosis kapitis. $^{43}$

Fasilitas merupakan salah satu faktor yang menjadi penyebab responden menjadi memiliki perilaku menggunakan barang pribadi bergantian dengan orang lain karena dengan keterbatasan biaya mereka diharuskan untuk hidup berbagi dengan orang lain disekitarnya. Selain bergantian menggunakan barang pribadi kepadatan hunian juga merupakan faktor yang penting. Menurut Keputusan Menteri Kesehatan Nomor 829/MENKES/SK/VII/1999 kamar tidur memiliki luas minimal $8 \mathrm{~m}^{2}$ perorang. Kamar tidur yang ditempati oleh anak panti dengan kapasitas $12-17$ orang adalah $4 \times 5 \mathrm{~m}^{2}$, dan kapasitas 25 orang adalah $15 \times 2,5 \mathrm{~m}^{2}$. Semakin padat suatu hunian, maka akan semakin mudah penularan suatu penyakit seperti pedikulosis kapitis. ${ }^{68}$

Hasil penelitian ini sejalan dengan penelitian Anggraini, yang menyatakan tidak terdapat hubungan tingkat pengetahuan pedikulosis kapitis dengan kejadian pedikulosis kapitis dengan nilai $\mathrm{p}=0,126$. Dijelaskan dalam penelitian ini bahwa orang yang memiliki pengetahuan yang tinggi tetapi tidak disertai kemauan dan tindakan untuk mengurangi penularannya untuk bersikap sesuai dengan tingkat pengetahuannya maka akan tetap bisa terjadi suatu penyakit seperti pedikulosis kapitis. ${ }^{59}$

\section{Hubungan Perilaku Penggunaan Sampo \\ Dengan Kejadian Pedikulosis Kapitis.}

Pada Tabel 2. Berdasarkan uji Fisher's Exact Test antara perilaku penggunaan sampo 
dengan kejadian pedikulosis kapitis didapatkan nilai $\mathrm{p}=0,274$ atau $\mathrm{p}>0,05$ sehingga $\mathrm{H}_{0}$ diterima yang menandakan bahwa tidak terdapat hubungan antara perilaku penggunaan sampo dengan kejadian pedikulosis kapitis.

Tabel 2. Hubungan Perilaku Penggunaan Sampo Dengan Kejadian Pedikulosis Kapitis

\begin{tabular}{ccccccc}
\hline & Perilaku & \multicolumn{4}{c}{ Kejadian Pedikulosis Kapitis } & Nilai p \\
\cline { 3 - 6 } No. & $\begin{array}{c}\text { Penggunaan } \\
\text { Sampo }\end{array}$ & Positif & $\%$ & Negatif & $\%$ & \\
\hline 1 & Baik & 18 & 81,4 & 4 & 18,3 & \\
2 & Kurang & 13 & 100 & 0 & 0 & 0,274 \\
\hline
\end{tabular}

Sumber : Data Primer, 2019

Salah satu pencegahan pedikulosis kapitis adalah dengan cara menjaga kebersihan kepala dan rambut salah satunya adalah dengan cara keramas menggunakan sampo. Hal ini karena Pediculus humanus capitis menyukai rambut dan kulit kepala yang lembab akibat kurangnya kebersihan rambut dan kulit kepala sehingga menyediakan lingkungan yang subur untuk berkembangnya kutu. ${ }^{18,34}$ Keramas menggunakan sampo adalah suatu tindakan pencegahan saja namun sampo sendiri tidak dapat membunuh kutu maupun telur. Sehingga dengan perilaku penggunaan sampo yang baik namun tidak dibarengi dengan pengobatan dan perilaku menggunakan barang pribadi yang baik maka tetap bisa terkena pedikulosis kapitis jika tinggal ditempat yang sama dengan orang yang terkena pedikulosis kapitis. ${ }^{18,35}$

Hasil penelitian ini juga sejalan dengan penelitian Dita, yang menyatakan tidak terdapat hubungan antara higiene cuci rambut terhadap kejadian pedikulosis kapitis dengan nilai $\mathrm{p}=0,100$. Faktor utama penyebab tidak efektifnya cuci rambut terhadap penanganan pedikulosis kapitis dikarenakan kandungan didalam sabun cuci rambut umumnya tidak terdapat kandungan yang secara spesifik dapat membunuh kutu rambut tersebut dan hal inilah yang dapat menyebabkan tidak terdapatnya hubungan antara frekuensi cuci rambut dengan kejadian pedikulosis kapitis. ${ }^{61}$

\section{KESIMPULAN}

Tidak Terdapat Hubungan Antara Tingkat Pengetahuan Dan Perilaku Penggunaan Sampo Terhadap Kejadian Pedikulosis Kapitis Di Panti Asuhan X Palangka Raya

\section{DAFTAR PUSTAKA}

1. Handoko RP. Pedikulosis, Dalam: Djuanda A, Ilmu Penyakit Kulit dan Kelamin, edisi VII. Jakarta: Balai penerbit FKUI; 2016: 134-7

2. Madke B, Khopkar U. Pediculosis capitis: an update. Indian $J$ of dermatol, venereo and lepro 2012; vol 78(4): 429-38.

3. Yousefi S. Shamsipoor F, Abadi YS. Epidemiological Study of Head Louse (Pediculus humanus capitis) Infestation among Primary School Students in Rural Areas of Sirjan County, South of Iran. Thrita J Med Sci 2012; 1(2): 53-6

4. Falagas ME, Matthaiou DK, Rafailidis PI, Panos G, Pappas G. Worldwide prevalence of head lice. Emerg Infect Dis J 2008; 14(9): 1493-4

5. Rassami W, Soonwera M. Epidemiology of Pediculosis Capitis Among School Childern in Eastern Area of Bangkok Thailand. Asian Pac J Trop Biomed. 2012; 9014

6. Bachok N, Nordin RB, Awang CW, Ibrahim NA, Naing L. Prevalence and associated factors of head lice infestation among primary school children in Kelantan, Malaysia. 2006; 37:536-43

7. Restiana R, Aminah S. Hubungan Berbagai Faktor Resiko Terhadap Angka Kejadian Pedikulosis Kapitis Di Asrama. Yogyakarta: Universitas Muhammadiyah. 2010

8. Rifqoh, Norsiah W. Pediculosis Capitis Dan Personal Hygiene Pada Anak SD Di Daerah Pedesaan Kotamadya Banjarbaru. Medical Laboratory Technology Journal. 2017: 58-62 
9. Lukman N, Armiyanti Y, Agustina D.

Hubungan Faktor-Faktor Risiko Pediculosis capitis

terhadap kejadiannya pada santri di Pondok Pesantren Miftahul Ulum Kabupaten Jember. Journal of Agromedicine and Medical Sciences. 2018; 4(2)

10. Ansyah AN. Hubungan Personal Hygiene Dengan Angka Kejadian Pedikulosis Capitis pada Santri Putri Pondok Pesantren Modern Islam Assalaam Surakarta. [Skripsi].

Surakarta: Fakultas Kedokteran Universitas Muhammadiyah Surakarta. 2013

11. Papalia DE, Olds SW, Feldman RD. Human Development. Jakarta: Salemba Medika. 2009

12. Lesshaft $\mathrm{H}$, Baier A, Guerra $\mathrm{H}$, Terashima A, Feldmeier $\mathrm{H}$. Prevalence and risk factors associated with pediculosis cappitis in an improverished urban community in Lima, Peru. Journal of Global Infectious Diseases Medknow Publication.2013; 5(4): 138-43.

13. Notoatmodjo S. Ilmu Perilaku Kesehatan. Jakarta: Rineka Cipta. 2010

14. Sutanto I, Ismid IS, Sjarifuddin PK, Saleha S. Buku Ajar Parasitologi Kedokteran edisi 4. Jakarta: Balai Penerbit Fakultas Kedokteran Universitas Indonesia. 2015; 300-1.

15. Frankowski B, Weiner L. Head Lice. USA: American Academy of Pediatrics, 2002.

16. Rupes V, Vlckova J, Mazanek L, Chmela J, Ledvinka J. Pediatric head lice: taxonomy, incidence, recistance, delousing. Epidemiol Mikrobiol Imunol Journal. 2006; 55(3)

17. Hadi UK, Soviana S. Ektoparasit: Pengenalan, Identifikasi, dan pengendaliannya. Bogor: IPB Press, 2010.

18. Sungkar, S. Pedikulosis dalam:
Hadidjaja P, Margonoss, editor. Dasar Parasitologi Klinik. Edisi I Jakarta: Fakultas Kedokteran Universitas Indonesia. 2011: 349-55.

19. Roberts R. Head lice. $N$ Engl J Med 2002; 346: 1645-50

20. Veracx A, Raoult D. Biology and Genetics of Human Head and Body Lice. Trends Parasitol 2012; 28(12): 563-71

21. Abdulla BS. Morphological Study and Prevalence of Head Lice (Pediculus humanus capitis) (Anoplura: Pediculidae) Infestation among Some Primary School Student in Erbil City, Kurdistan region. Zanco J Pure Appl Sci. 2015; 27(5): 29-36

22. Marjan KSN, Koyee QMK, Abdulla SMA. In Vitro Study On The Morphological Development Of Eggs (Nits) and Other Stages Of Head Lice Pediculus humanus capitis De Geer. Zanco J Pure Appl Sci. 2015: 27(3): $35-40$

23. Finlay J, MacDonald NE [Canadian Paediatric Society]. Head Lice Infestation: A Clinical Update. Paediatr Child Health 2008; 13(8): 692-6

24. Centers for Disease Control and Prevention. Parasites. 2015. Available from: https://www.cdc.gov

25. Veraldi S. Head Lice in African Childern. G Ital Dermatol Venereol 2018;153(4): 580-1.

26. Chosidow O. Scabies and Pediculosis. Lancet. 2000:355:819-826. Flinder DC, Schweinitz PD. Pediculosis and scabies. Am Fam Physician. 2004; 69(2): 341-4.

27. Stone SP, Jonathan NG, Rocky EB. Scabies, Other Mites and Pediculosis. In: Feedberg IM, Editors: Fitzpatrick's Dermatology in General Medicine volume 2 eighth edition. USA: The Megraw-Hill. 2012: 25738. 
28. Hansen RC. Overview: The State of Head Lice Management and Control. Am J Of Manag Care. 2004.

29. Speare R, Canyon DV, Melrose W. Quantification of Blood intake of The Head Louse: Pediculus humanus capitis. Int J Dermatol 2006; 543-6

30. Burgess IF, Ciara SC. Head Lice. Dalam: Thomas Diepgen, Michael Bigby editors. Evidence-Based Dermatology Second Edition. Britain: Hywell Williams 2008; p.471-6

31. Frydenberg A, Starr M. Head lice. Australian Family Physician. 2003; 32:607-11

32. Natadisastra D, Ridad A. Parasitologi Kedokteran: Ditinjau dari organ tubuh yang diserang. Jakarta: EGC. 2009

33. Borges R, Mendes J. Epidemiological aspect of head lice in children attending day care centres, urban and rural schools in Uberlandia, Central Brazil. Mem last Oswaldo Cruz, Rio de

Janeiro. 2002; 97(2): 189-92. Available from: http://www.ncbi.nlm.nih.gov

34. Burkhart CN, Burkhart CG. Scabies, Other Mites and Pediculosis. In: Goldsmith LA, Katz SI, Gilchrest BA, Pallen AS, leffel DJ, Wolff K, (editors). Fittzpatrick's Dermatology in General Medicine. 8th ed, New York; McGraw-Hill. 2012: 2573-6

35. Ohio Department of Health. Pediculosis. Ohio: Department of Health. 2014; 1-15

36. Habif TP. Pediculosis. In: Weller C, John A, Hunter A, Savin J, Dahl M. Clinical Dermatology Fourth Edition. British: Willey-Blackwell Publication 2004; 228-42

37. Theresa A. Lice Found on Humans. Virginia: Department of Entomology, Virginia State University. 2015

38. Burns DA. Diseases Caused by Arthropods and Other Noxious Animals. In: Burns T, Breathnach S,
Cox N, Griffiths C eds. Rook`s Textbook of Dermatology Eight Edition Volume 2. United Kingdom: Willey-Blackwell Publication. 2004: 446-8.

39. Frankowski B, Weiner L. Head Lice. USA : American Academy of Pediatrics. 2002

40. Gunning K, Pippitt K, Kiraly B, Sayler M. Pediculosis and Scabies: A Treatment Update. Indian Journal of Clinical Practice. Utah: University of Utah School of Medicine. 2013

41. Tim Penyusun Kamus Pusat. Kamus Besar Bahasa Indonesia. Jakarta: Balai Pustaka. 2002

42. Notoatmodjo S. Kesehatan Masyarakat Ilmu dan Seni. Jakarta: Rineka Cipta. 2007

43. Budiman, Riyanto A. Kapita Selekta Kuisioner Pengetahuan dan Sikap

Dalam Penelitian Kesehatan. Jakarta: Salemba Medika. 2013

44. Dewey J. Democracy and Education, Fourth edition. New York: The Macmillan Company. 2003

45. Enda. Ilmu Perilaku Kesehatan. Jakarta: Rineka Cipta. 2010

46. Arikunto S. Prosedur Penelitian Cetakan Ke-15. Jakarta: PT. Rineka Cipta. 2013

47. Sarwono S. Sosiologi Kesehatan Beberapa Konsep Serta Aplikasinya. Yogyakarta: Gadjah Mada University Press. 1993

48. Potter,Perry. Fundamental Keperawatan. Jakarta: EGC. 2005

49. D'Souza, P. and Rathi, S.K. Shampoo and conditioners: What a dermatologist should know?. Indian J Dermatol. 2015: 248-54.

50. Tranggono RI, Latifah F. Buku Pegangan Ilmu Pengetahuan Kosmetik. Jakarta: PT Gramedia Pustaka Utama. 2007 
51. Maryunani A. Perilaku Hidup Bersih dan Sehat (PHBS). Jakarta: CV. Trans Info Media. 2013

52. Notoadmodjo S. Metodologi Penelitian Kesehatan. Jakarta: Rineka Cipta. 2012

53. Riyanto A. Aplikasi Metodologi Penelitian Kesehatan cetakan II. Yogyakarta: Nuha Medika. 2017

54. Arrizka I. Pengetahuan, Perilaku dan Sikap Santri Terhadap Pedikulosis Kapitis Di SMA Islam Terpadu Raudhatul Ulum Indralaya [Skripsi]. Palembang: Fakultas Kedokteran Universitas Muhammadiyah Palembang. 2015

55. Tim Penyusun. Petunjuk penulisan usulan penelitian, skripsi dan naskah publikasi. Palangka Raya: Fakultas Kedokteran Universitas Palangka Raya. 2016.

56. Sugiyono. Metode Penelitian Pendidikan (Pendekatan Kuantitatif, Kualitatif, dan R\&D). Bandung: Alfabeta. 2016

57. Oktavia N. Sistematika Penulisan Karya Tulis Ilmiah. Yogyakarta: Deepublish. 2015

58. Prihanti GS. Pengantar Biostatistik. Malang: UMM Press. 2018

59. Anggraini A. Hubungan Tingkat Pengetahuan dan Personal Hygiene terhadap Kejadian Pedikulosis Kapitis pada anak asuh di Panti Asuhan Liga Dakwah [Skripsi]. 2018: 131-6

60. Gunarso W. Bahan Pengajaran Mikroteknik. Bogor: DEPDIKBUD IPB. 1989

61. Dita TS. Hubungan karakteristik rambut dan higiene cuci rambut dengan Pedikulosis Kapitis Pada Santri Di Pondok Pesantren Aulia Cendekia Talang Jambe Sukarami Palembang [Skripsi]. Palembang: Fakultas Kedokteran Universitas Sriwijaya. 2016
62. Riyanto A. Pengolahan dan Analisis Data Kesehatan. Yogyakarta: Nuha Medika. 2009

63. Panti Asuhan X. Profil Panti Asuhan X Palangka Raya. 2018

64. Depkes RI. Profil Kesehatan Indonesia. Jakarta: Departemen Kesehatan Republik Indonesia. 2009

65. Soetjaningsih K. Tumbuh Kembang Remaja dan Permasalahannya. Jakarta: Sagung Seto. 2004

66. Aisy R. Hubungan Tingkat Pengetahuan dan perilaku pencegahan terhadap angka kejadian penyakit pedikulosis kapitisdi pondok pesantren X. [Skripsi]. Surakarta : Fakultas Kedokteran Universitas Muhammadiyah Surakarta. 2018

67. Menteri Kesehatan RI. Keputusan Menteri Kesehatan Republik Indonesia Nomor 829/MENKES/SK/1999. 1999

68. Ary BW, Natalia D, Fitriangga A. Gambaran Dan

Hubungan Karakteristik Individu Dan Frekuensi Cuci Rambut Dengan Kejadian Pedikulosis Kapitis Di Pondok Pesantren X Kecamatan Mempawah Timur. Jurnal Cerebellum. 2019; 2(2): 1296-1306.

69. Setyoasih A, Suryani D. Hubungan Antara Pengetahuan, Personal Hygiene, Dan Infestasi Pediculus humanus var. capitis Pada Santriwati Muhammadiyah Boarding School Prambanan Sleman Yogyakarta. Jurnal Kedokteran dan Kesehatan. 2016; 12(2): 190-201

70. Nurmatialila W, Widyawati, Utami A. Hubungan Antara Tingkat Pengetahuan mengenai pedikulosis kapitis dan praktik kebersihan diri dengan kejadian pedikulosis kapitis pada siswa SDN Tunggak Kecamatan Toroh Kabupaten Grobogan. Jurnal Kedokteran Diponegoro. 2019; 8(3): 1081-91 